\title{
In Search of the Vaccine Against Chagas Disease: A Tedious Road of More Than 100 Years
}

\author{
Domínguez-Guillén A $\mathrm{A}^{\text {1,2 }}$, López-Domínguez J 2,3, \\ Ochoa-Martínez $\mathbf{P}^{2}$, López-Monteon $\mathrm{A}^{2,4}$ and \\ Ramos-Ligonio $\mathbf{A}^{2,4 *}$ \\ 1Doctorado en Ciencias Biomédicas, Xalapa, Veracruz, \\ México \\ ${ }^{2}$ LADISER, Inmunología y Biología Molecular, Facultad \\ de Ciencias Químicas, Universidad Veracruzana, Orizaba, \\ Veracruz, México \\ ${ }^{3}$ Universidad Politécnica de Huatusco, Ingienería en \\ Biotecnología, Huatusco De Chicuellar, Veracruz, México \\ ${ }^{4}$ Asociación Chagas con Ciencia y Conocimiento A.C. \\ Orizaba, Veracruz, México \\ *Correspondling author: Angel Ramos-Ligonio, \\ LADISER, Inmunología y Biología Molecular, Facultad de \\ Ciencias Químicas, Edificio D, Universidad Veracruzana, \\ Orizaba, Veracruz, México
}

Received: April 30, 2021; Accepted: May 22, 2021; Published: May 29, 2021

\begin{abstract}
Chagas disease is a neglected and widely distributed parasitic disease in America, caused by Trypanosoma cruzi parasites. Currently, there are 6 to 7 million infected people and between 60 to 80 million people remain at risk of infection in endemic areas. Normally the infection does not manifest itself in the acute phase or it does so in a mild and nonspecific way, but several years later infected people suffer from heart or digestive system problems with varying degrees of disability and even death. In the acute stage of the infection, there are treatments with antiparasitic drugs that are effective and that are why it is very important to treat children who are born infected. During the chronic phase, on the other hand, the effectiveness of the treatment has been much debated by experts, and recent multicenter studies carried out throughout Latin America showed that, although drugs eliminate the parasite, they are not effective in preventing the development of the illness. Therefore, it is an urgent need to have new strategies to control the infection and the development of the disease, therefore, the objective of achieving a vaccine that not only prevents primary infection (when the parasite comes into contact with the body) but also controls the progression of the disease in infected people and reverses the damage associated with the infection by that obtaining a vaccine is imperative. This work aims to highlight the efforts, progress and show the different approaches in the development of the vaccine against $\mathrm{ChD}$.
\end{abstract}

Keywords: Trypanosoma cruzi; Vaccine; Neglected tropical disease; Parasite; Trypanosomiasis

\section{Abbreviations}

ChD: Chagas disease; T. cruzi: Trypanosoma cruzi; NFX: Nifurtimox; BZN: Benznidazole; MASP: Mucin-Associated Surface Proteins; Tc24, Tc52, TcG1, TcG2, TcG4, T. cruzi antigens; TSA-1: Trypomastigote Surface Antigen 1; DTU's: Discrete Typing Units; TcI-TcVI: DTU's of T. cruzi; GPI: Glycosylphosphatidylinositol; IL-12: Interleukin-12; IL-10, Interleukin-10; GM-CSF: Granulocyte and Monocyte Colony Stimulating Factor; TS: Transialidase; ASP2: Amastigote Surface Protein-2; SARS-CoV-2: Type 2 Coronavirus causing Severe Acute Respiratory Syndrome; VLP: Virus-Like -Particles; TLR9: Toll-Like Receptor-9; TGF- $\beta$ : Transforming Growth Factor Beta; TLR2: Toll-Like Receptor-2; CD40: Cluster of Differentiation 40; CD4: Cluster of Differentiation 4; CD8: Cluster of Differentiation 8; DNA: Deoxyribonucleic Acid; mRNA: Messenger Ribonucleic Acid; cDNA: Complementary Deoxyribonucleic Acid; CpG: Cytosine And Guanine Rich DNA Regions; WHO: World Health Organization

\section{Background}

More than 110 years after its discovery, Chagas Disease (ChD) or American Trypanosomiasis is considered by the World Health Organization (WHO) as one of the neglected tropical diseases. This disease affects about 10 million people worldwide [1], most of those affected are poor and marginalized people living in rural areas of developing countries [2]. It is caused by the Trypanosoma cruzi parasite that is transmitted mainly by triatomine bites. Skin bite lesions, or permissive mucosal and conjunctival surfaces, are in contact with triatomine feces that contain the parasite in its trypomastigote form, infecting neighboring cells, entering the bloodstream, and leading to systemic complications, such as cardiomyopathies and enteropathies $[3,4]$. Other forms of transmission of the parasite can be by blood transfusion [5], orally [6], transplacental route from infected mothers [7], by transplantation of infected organs, and accidentally [8]. Recently, several studies suggest that $T$. cruzi can be spread through sexual transmission [9-11]. This pathology can appear in its acute and/or chronic form, which can be symptomatic or asymptomatic, mainly affecting the heart and digestive system and its importance lies in the fact that it produces disability and sudden death in apparently healthy people. It is estimated that each year between 10,000 and 12,500 people die from this disease, with cardiac complications the main cause of these deaths [12]. Initially, $\mathrm{ChD}$ was endemic to the American continent, but due to the various forms of transmission and social phenomena such as the migration of infected people, it has spread to continents such as Europe, Asia and Oceania; becoming a major health problem worldwide $[13,14]$. However, although there is a treatment for this disease, the available drugs have low efficacy and very serious side effects. These drugs are very effective in the acute stage of ChD infection, but less effective in the chronic stage [15]. In addition, many patients do not present symptoms immediately after infection, so the years may go by and they are only diagnosed when they already have heart and/or digestive disorders, and it is at this time that the drugs lose their effectiveness [12,16-18]. Vaccination is the cheapest strategy to prevent infectious diseases and a commercial
Austin J Infect Dis - Volume 8 Issue 2 - 2021

Submit your Manuscript | www.austinpublishinggroup.com

Ramos-Ligonio et al. (C) All rights are reserved
Citation: Domínguez-Guillén A, López-Domínguez J, Ochoa-Martínez P, López-Monteon A and Ramos-Ligonio A. In Search of the Vaccine Against Chagas Disease: A Tedious Road of More Than 100 Years. Austin J Infect Dis. 2021; 8(2): 1049. 
vaccine against $\mathrm{ChD}$ is not yet available. Multiple vaccine prototypes have been tested and have shown to be good candidates in terms of protection and with great advantages for their production and application [19-24]. During infection, the immune response that is generated against the parasite is not enough to neutralize and/ or eliminate it, this being the main factor in the persistence of the parasite as well as the development of the chronic phase of the disease; where the parasite load and the unbalance of oxidative stress generate the damage in the host tissue [25], therefore, the control of T. cruzi by activating the immune system during the acute phase of the disease would prevent the development of the pathology [26]. This work aims to highlight the efforts, progress and show the different approaches in the development of the vaccine against $\mathrm{ChD}$.

\section{Overview of Vaccinology in Chagas disease}

Current control measures for protozoal infection rely solely on chemotherapy to improve the disease. Vector control is also helping to reduce the transmission of infections by this type of parasite. To date, no reliable vaccines are available against these infections, and there is also an alarming increase in drug resistance [27]. As is the case of the ChD [28]. Developing a vaccine is a long and complex process that often takes 10-15 years, and involves the combined participation of public and private organizations. Vaccine development and testing follow a standardized set of steps. The early stages are exploratory. Regulation and oversight increase as the candidate vaccine progresses through the process $[29,30]$. Initially, the development of a vaccine for $\mathrm{ChD}$ was slow and cautious due to considerations regarding autoimmunity as a potential cause of pathogenesis [31], however, it has recently been suggested that the persistence of the parasite in the host plays a key role in disease progression and pathogenesis [32,33] These studies have shown that in animal models control of T. cruzi can be achieved during the disease [31] and these advances have increased and accelerated the search for a vaccine as a treatment for ChD [34].

\section{Complete Parasites (Inactivated, Live, or Attenuated)}

For various pathogens, one of the most common and traditional strategies in vaccines is the use of inactivated or attenuated pathogens [35], for the case of T. cruzi some have been tested with a certain margin of success [36,37], vaccines that used whole parasites to combat $\mathrm{ChD}$ have been evaluated in initial studies with mixed results, but these types of vaccines are difficult to implement $[38,39]$.

\section{Subunit Vaccines (Recombinant Proteins)}

Many recombinant antigens derived from T. cruzi have been generated using various prokaryotic and eukaryotic hosts $[21,40,41]$. Antigens such as TSA1, Tc24, TcG1, TcG2, TcG4, Tc52, Cruzipain, ASP2, Trans-Sialidase (TS), are examples of genes used for the development of recombinant proteins and that have been used as vaccine candidates [21,42-47]. A key challenge for the development of not only vaccines with recombinant proteins against $T$. cruzi is the activation of $\mathrm{CD}^{+}$cells and $\mathrm{CD} 4^{+}$cells of the Th1 subpopulation [4850]. Therefore, multiple adjuvants have been tried to bias the immune response towards such a cellular response. Among the advantages of this type of vaccine candidate is the easy production, however, some disadvantages such as performance, the formation of inclusion bodies during their purification, the lack of adequate post-translational modifications [51], and contamination with endotoxins due to the use of bacteria for their production are some points to take into account and that must be resolved so that these vaccine candidates have better availability and safety $[52,53]$.

\section{DNA Vaccines}

DNA vaccines have been used in mouse and dog models that carry genes encoding T. cruzi antigens and have been shown to reduce parasitemia and increase survival rates [42-45]. However, despite the ease of construction and production of vectors, the stability of DNA, the easy production and administration of vaccines, and the ability to enhance the immune response through the co-administration of genes encoding cytokines such as IL-12, GM-CSF, or costimulation molecules such as CD40 [54-56]. CpG motifs have also been used as adjuvants that can activate the production of Th1 cytokines through the TLR9 pathway [57-59]. Some preclinical studies have highlighted the importance of its administration being combined with recombinant proteins to improve immunogenicity [42]. Most importantly, the administration of antigens by DNA vaccination has been shown to be effective in inducing the production of antibodies, Th1 cytokines, and $\mathrm{CD} 8^{+} \mathrm{T}$ cell-mediated immune responses $[54,55]$.

\section{Synthetic Peptides}

The identification of epitopes in proteins recognized by medically relevant antibodies is useful primarily for the development of diagnostic tests [59-62], however, some peptides have been used as vaccine candidates. T. cruzi is coated by a thick layer of Glycosylphosphatidylinositol (GPI) -anchored glycoproteins, such as mucins, Mucin-Associated Surface Proteins (MASP), and TransSialidase (TS)/gp85 glycoproteins. MASP is the second largest gene family, accounting for approximately $6 \%$ of the T. cruzi genome $[63,64]$. Overlapping B and T cell epitopes of this protein by using synthetic peptides were able to control T. cruzi infection in mice by inducing humoral and cellular immunity [65].

\section{Reverse Vaccination}

Previously, in the development of conventional vaccines, the process began with the cultivation of the microorganism, which could be complicated according to the pathogen as well as the biological risks during process, Subsequently, the components or structures capable of generating an immune response were identified, the process could be long and tedious since it is based on trial and error until the candidates for the vaccine are found [66]. An alternative strategy that seeks to solve the difficult implementation of vaccines for inactivated or attenuated pathogens, or for vaccine candidates made up of subunits (recombinant proteins or cDNAs) is based on the section of antigens [67]. What makes the identification of antigens a key point in the development of effective vaccines, previously it was one of the processes in which more time was invested, but now the approach of reverse vaccinology with the help of bioinformatics and genomic analyzes and proteomics of T. cruzi $[63,68]$ have facilitated, accelerated and diversified the number of candidate antigens [69]. In this sense, the development of vaccines from the knowledge of the genome of pathogens has increasingly gained ground due to the advantages that this represents. A clear example of the use of reverse vaccinology is its use in the development of the vaccine against SARS- 


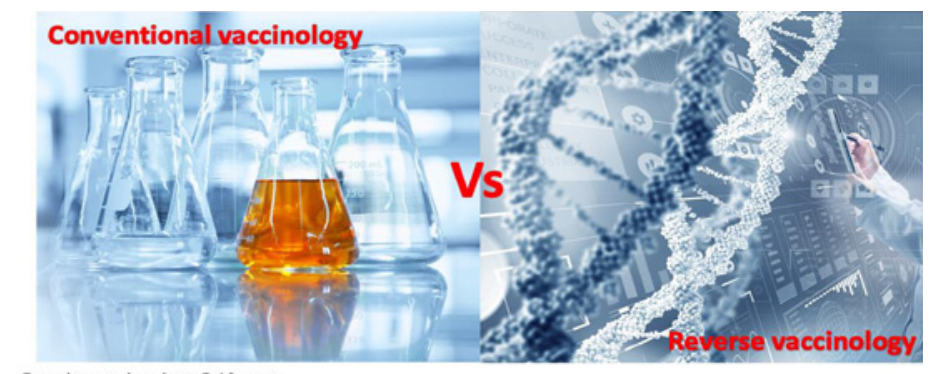

Experimentation time: 5-10 years

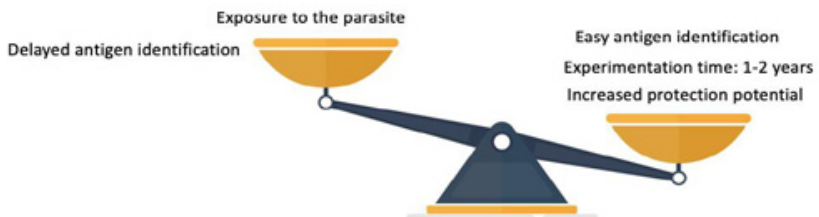

Figure 1: The use of reverse vaccinology in the development of the vaccine for Chagas disease. In conventional vaccinology, the microorganism is cultivated, the next step is the identification and selection of conserved antigens, which takes a great deal of time and the experimental part is trial and error. On the other hand, reverse vaccinology starts with the sequencing of the genome and proteome, later, through bioinformatic and immunomic analyzes, potential antigens are identified, once the candidates are selected, they are cloned and expressed to make way for the studies immunogenicity tests in animal models to evaluate safety and efficacy (preclinical phase) and then in humans (clinical phase). The implementation of new technologies in reverse vaccinology considerably reduces the time in the development of the vaccine.

CoV-2, wherefrom genome sequencing and in silico analysis using computational methods for the prediction and design of vaccines [70], a large number of vaccine candidates was generated, developing (because of the critical situation), a vaccine approved and applied in less than 1 year for this virus [71], demonstrating the potential of this approach having a significant impact on reducing the time required for vaccine development and minimizing adverse effects $[67,69,72,73]$. Now with reverse vaccinology, it is no longer necessary to culture the parasite, from the information of the genome and proteome in databases, the analysis and selection of antigens are made using different prediction tools [74,75], later they are synthesized to be used in experimental animal models and to evaluate the capacity to activate the immune response [76]. The objective of this type of approach is the identification of the minimum essential information for the prediction of antigens with the greatest protection potential against the pathogen in question, with the optimization of this new approach, the time could be reduced by up to one or two years of experimentation (Figure 1) [77].

\section{Other Vaccine Alternatives}

The development of vaccines for the control of $\mathrm{ChD}$ is an urgent need and the main challenge lies in the biological complexity of the parasite, characterized mainly by the stages of its life cycle, which is why the search for antigenic candidates for the design of vaccines represent a big problem. Therefore, the application of technology including Virus-Like -Particles (VLP) has become an interesting tool for the development of vaccines [78]. The structural conformation of VLPs mimics the morphology and structures of viral particles. One of their main advantages as vaccine prototypes is safety since the particles do not count the virus genome and, therefore, are not infectious viral particles, and the ability to induce a robust immune response [79-82]. In addition, there are several ways to produce recombinant VLPs through the expression of genes in systems of bacteria, fungi, insects, mammalian cells, among others, but this will depend on the biology of the viral particle $[83,84]$. On the other hand, from a biotechnological point of view, plants have opened up new low-cost strategies to develop affordable vaccines against parasitic diseases, such as malaria, leishmaniasis, toxoplasmosis, among others [85]. In this sense, carrots, papaya, lettuce, and tobacco have been used to express antigens derived from parasites in the nucleus or the chloroplast of cells [86]. The low cost of plant-based vaccine technology represents a great opportunity for governments in poor or middle-income countries that have serious parasitic disease problems but are not served by the pharmaceutical industry (Figure 2).

\section{What Should be Taken into Account, Where are we and where are we Going?}

The remarkable advance in DNA sequencing has provided more and more extensive information on the genome of various strains of T. cruzi, improving the ability to identify antigens [31,86-89]. This type of information is essential since it is well known that one of the main characteristics of T. cruzi is its wide genetic and antigenic variability. It is currently classified by molecular techniques into 7 lineages called Discrete Typing Units (DTU's) TcI-TcVI and TcBat $[90,91]$. Large amounts of experimental data show great heterogeneity between strains of T. cruzi in various parameters: biological, biochemical, parasitemia, virulence, tissue tropism, drug susceptibility, and immune response [92]. However, there is still controversy between the possible association that has been suggested of this genetic diversity with the heterogeneity in various parameters with the evolution of the infection, clinical manifestations, and treatment during $\mathrm{ChD}$ [93]. Overlooking genetic variability during drug development, evaluation, and optimization is not recommended [94]. This same recommendation is suggested during the antigen search (antigen conservation) because all DTU's have been reported in human infections with some genotypes less frequently than others. Therefore, a vaccine must seek to protect against a wide variety of genotypes [30].

The objective of the $\mathrm{ChD}$ vaccine should be to act on the two 


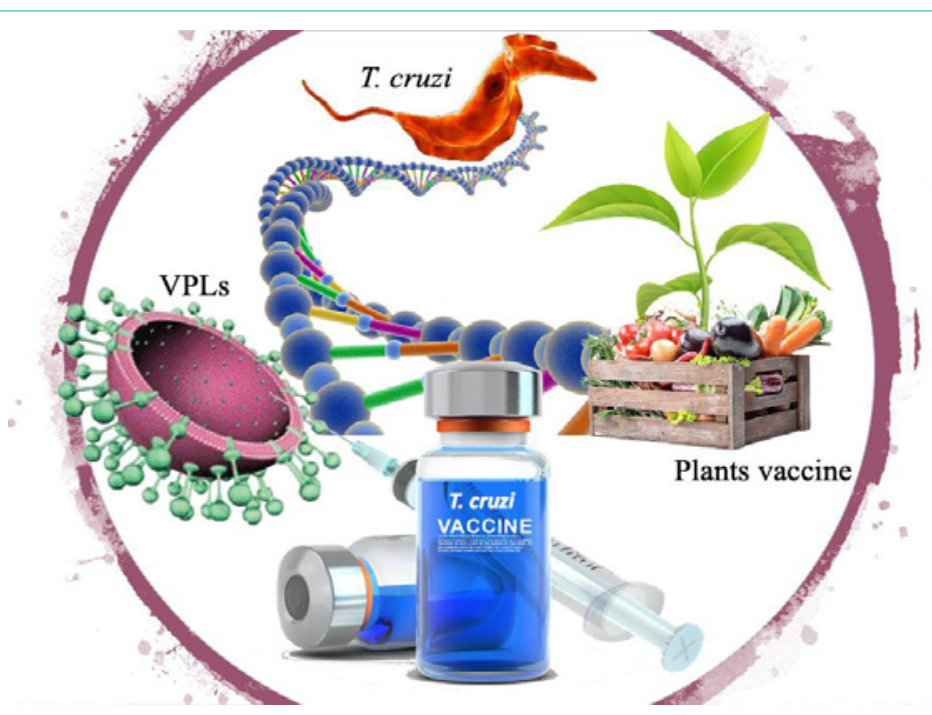

Figure 2: New technological alternatives for the development of vaccines for Chagas disease. In addition to being potential vaccines against the viruses from which they are derived, VLPs can also be used to present individual epitopes of other organisms to the immune system. This can be done by gene fusion and subsequent expression of the resulting recombinant protein or by chemical conjugation between the target antigen and the VLPs-generating structural protein. On the other hand, the low cost of plant-based vaccine technology represents a great opportunity that together with VLPs offer new perspectives in vaccine development.

different phases of the parasite, trypomastigotes (infective phase) and amastigote (intracellular replicative phase), managing to prevent infection and the spread of T. cruzi to control parasitemia [95]. For the development of vaccines against T. cruzi, VLPs represent a good alternative to generate good immune responses in a targeted way, since the resistance and susceptibility mechanisms of these infections are related to the polarization of the immune response that occurs during a natural infection, specifically during the acute phase. With this type of vaccines, a greater amount of the selected antigen could be expressed compared to that expressed naturally by the parasite, in addition to the fact that they can be coupled to other components that help develop immunogenicity and allow a much more robust immune response [96].

\section{Therapeutic or Prophylactic?}

There are two ways to approach $\mathrm{ChD}$ vaccine development from a prophylactic and therapeutic perspective. It is difficult to decide which is the best approach to address $\mathrm{ChD}$ due to the solutions involved. The area's most affected by $\mathrm{ChD}$ are poor areas and the majority of those infected never receive a diagnosis or treatment [85]. Therefore, in this scenario, the benefits that a prophylactic vaccine could provide stand out. In this scenario, economic studies project that a prophylactic vaccine to prevent or reduce heart disorders could represent only $20 \%$ of the costs of treatment annually. In the context of a disease associated with socioeconomic indicators such as poverty, a low-cost prophylactic vaccine is considered the best option [86,9799]. However, more studies are needed because socioeconomic indicators suggest that affected populations have less access to basic and general health services; In this sense, how valid is it to take as a reference the costs of cardiac treatments to which only some patients have access?. In addition to this, it is a reality that these indicators are also associated with cultural factors that do not allow approval of the use of vaccines by the most affected populations [100-103].

On the other hand, the therapeutic approach [104] has proposed the application of vaccines alone or in conjunction with chemotherapy. Vaccine-chemotherapy treatment is one of the most promising strategies to counteract the deficiencies posed by drugs for the treatment of $\mathrm{ChD}$ [99]. In the context of a disease that has treatments with efficacy delimited by the phase of the disease [105], long treatments and associated with serious adverse effects that end up impacting non-compliance with the treatments [17] a prophylactic vaccine combined with chemotherapy suggests a quite feasible solution $[4,106]$. Pre-clinical studies in mice have shown decreased parasitic load in heart fibrosis and cardiac pathologies [18,105-107]. In addition to this, it is suggested that this strategy could reduce the duration and dosage of the medications currently used, bringing as a benefit the reduction of adverse events, favoring the rates of completed treatments [33]; likewise, indirectly delaying the appearance of strains with resistance induced by exposure to Nifurtimox (NFX) and Benznidazole (BNZ). However, to dimension this approach, two questions must be raised to consider: Regardless of a possible vaccine-chemotherapy strategy, the affected populations have little access to treatment and, on the other hand, the application of the therapeutic approach implies a huge advance in diagnostic deficiencies that are still presented.

During the acute phase of T. cruzi infection, the parasite replicates extensively and releases immunomodulatory molecules that delay or polarize specific parasite responses mediated by effector $\mathrm{T}$ cells. This avoidance mechanism allows the parasite to spread in the host. In the chronic phase, the TGF- $\beta$ signaling pathway involved in tissue regeneration is affected. As a consequence, the death and replication rates of the parasites are very similar to what occurs during the acute phase of infection. T. cruzi is adapted to coexist with a vigorous immune response mounted by $\mathrm{CD} 8^{+} \mathrm{T}$ cells, calling into question the efficacy of conventional vaccines [108]. Early work shows that $T$. cruzi suppresses lymphocyte activation [109], an effect that depends on the density of the parasites. Therefore, the suppression induced by parasite molecules is more relevant in the acute phase, when the 
Therapeutic or prophylactic vaccine?

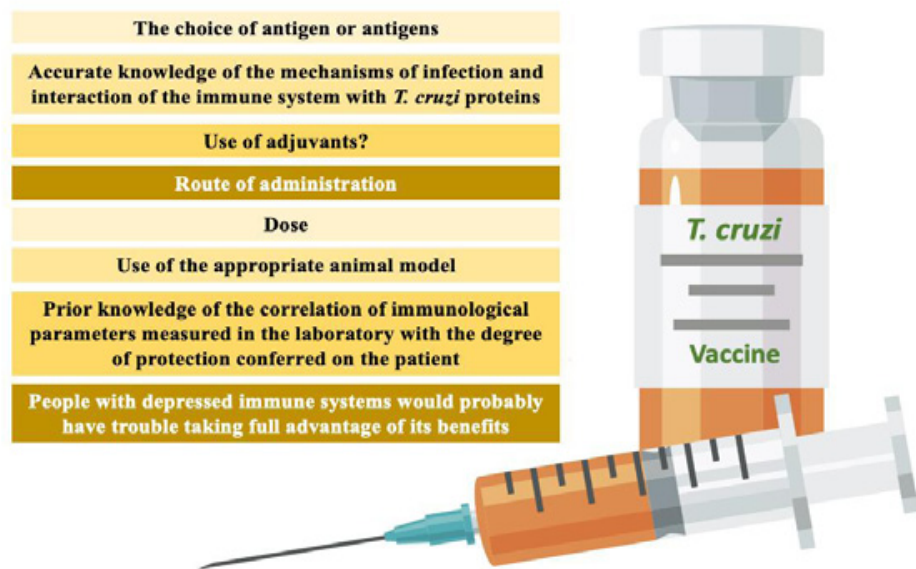

Figure 3: What should be taken into account for the development of the vaccine against Chagas disease.

concentration of such molecules can be quite high. Furthermore, T cell depletion can be observed at the peak of parasitemia [110]. In this sense, for example, cruzipain can induce the secretion of IL-10 and TGF- $\beta$, as well as the expression of arginase by macrophages, which leads to an increase in the intracellular replication of T. cruzi. Tc52 induces an inflammatory response because it is through TLR2 and only confers protection when combined with adjuvants. In the absence of adjuvants, Tc52 increases IL-10 mRNA in macrophages, which is a macrophage-inactivating cytokine. Furthermore, the expression of Tc52 appears to be necessary for optimal replication of T. cruzi in the host [110-112]. Other molecules such as mucins, including the trans-sialidase families, which are abundant in the parasite membrane, induce a state of immunosuppression in the host specifically in T cells, due to the absence of IL-2 and cause dysfunctional functioning in dendritic cells [113]. These behaviors should be taken into account for the use of these proteins as candidates in therapeutic cows. On the other hand, in most cases, the specific immune response generated against $T$. cruzi does not eliminate the parasite efficiently and its persistence is generated in the host, this being a factor for the appearance of the pathology in the chronic phase, this is why the elimination of the parasite in the acute phase would be of importance in preventing the survival of the parasite and preventing the development of chagasic pathologies. In this sense, prophylactic vaccination would be more appropriate [25].

It should be noted that a limitation in a large part of the vaccine candidates evaluated is that they have been mainly tested in murine models, so it is unknown whether this observed efficacy is similar in humans. This leads to the use of other animal models, such as dogs [115], non-human primates [25], as well as the cellular response in chagasic patients [20], and mixed therapy trials have been carried out where low-dose chemotherapeutic treatment is combined with the application of vaccines [4], which in some cases it reduces heart disease [21] in others oxidative damage is controlled, observing a cardioprotective effect [116-118].

Finally, vaccines are developed, tested, and regulated in much the same way as other drugs. In general, vaccines have more meticulous testing than drugs because, in general, there are more humans in clinical trials of vaccines, so do not underestimate the efforts made by different consortia and initiatives that develop candidate's vaccines, since these only aim to reduce the transmission and socioeconomic impact of ChD (Figure 3) [119-121].

\section{Conclusion}

Recent efforts have been made to evaluate the $\mathrm{T}$ cell epitope response of defined parasites to examine the molecular basis of the immune reaction elicited during infection with protozoan parasites. The severity of the infection is a function of the infecting species together with the consequent inflammatory and immune responses and the genetics of the host. This has been observed with the use of animal models. Studies in computational models suggest that the vaccine against $T$. cruzi would be economically viable, reducing costs in therapies used to combat Chagas' cardiomyopathy, as well as in the prevention of congenital transmission, thus, the development of a vaccine will contribute to prolonging the life of patients with higher quality, by halting the progression of the disease and for its distribution in low and middle-income countries where this disease is endemic and above all, by having a positive impact on health systems that invest large amounts of resources in your attention. One reason for the lack of parasitic vaccines could be low profitability for the pharmaceutical industry. Consequently, research is crucial to generate inexpensive vaccines since the development of new technologies could propose different approaches as well as new and diverse vaccine candidates to address the development of the vaccine against $\mathrm{ChD}$.

\section{References}

1. Chagas disease (also known as American trypanosomiasis). 2021.

2. Apt W. Treatment of Chagas disease. In: Tellerı'a J, Tibayrenc M, editors. American Trypanosomiasis Chagas Disease: One Hundred Years of Research. Elsevier. 2017: 751-771.

3. Zeledón R, Alvarado R, Jirón LF. Observations on the feeding and defecation patterns of three triatomine species (Hemiptera reduviidae). Acta Trop. 1977; 34: 65-77. 
4. Pérez-Molina JA and Molina I. Chagas disease. Lancet. 2018; 34: 65-77.

5. Botero LA, Mejía AM, Triana O. Caracterización biológica y genética de dos clones pertenecientes a los grupos I y II de Trypanosoma cruzi de Colombia. Biomedica. 2007; 27: 64 .

6. Toso M A, Vial UF, Galanti N. Transmisión de la enfermedad de Chagas por vía oral. Rev Med Chil. 2011; 139: 258-266.

7. Dumonteil E, Herrera C, Buekens P. A therapeutic preconceptional vaccine against Chagas disease: $A$ novel indication that could reduce congenital transmission and accelerate vaccine development. PLoS Negl Trop Dis. 2019; 13 .

8. Salvador F, Sánchez-Montalvá A, Sulleiro E, Moreso F, Berastegui C, Caralt $M$, et al. Prevalence of Chagas disease among solid organ-transplanted patients in a nonendemic country. Am J Trop Med Hyg. 2018; 98: 742-746.

9. Hecht MM, Nitz N, Araujo PF, Sousa AO, Rosa A de C, Gomes DA, et al. Inheritance of DNA transferred from American trypanosomes to human hosts. PLoS One. 2010; 5

10. Araujo PF, Almeida AB, Pimentel CF, Silva AR, Sousa A, Valente SA, et al. Sexual transmission of American trypanosomiasis in humans: a new potential pandemic route for Chagas parasites. Mem Inst Oswaldo Cruz. 2017; 112: 437-446

11. Bonomo A, Savino W. T cell activation in utero: self or non-self discrimination Ann Transl Med. 2015; 3: 65

12. MacLean LM, Thomas J, Lewis MD, Cotillo I, Gray DW, De Rycker M Development of Trypanosoma cruzi in vitro assays to identify compounds suitable for progression in Chagas' disease drug discovery. PLoS Negl Trop Dis. $2018 ; 12$

13. Rassi A Jr., Rassi A, Marin-Neto JA. Chagas disease. Lancet. 2010; 375 1388-1402

14. Ramos-Ligonio A, López-Monteon A. Chagas disease: Migration and transmission mechanisms; myths and realities. Edorium J Cell Biol. 2015 2: 4-7.

15. Pecoul B, Batista C, Stobbaerts E, Ribeiro I, Vilasanjuan R, Gascon J, et al. The BENEFIT trial: Where do we go from here? PLoS Negl Trop Dis. 2016; 10 .

16. Wilkinson SR, Taylor MC, Horn D, Kelly JM, Cheeseman I. A mechanism for cross-resistance to nifurtimox and benznidazole in trypanosomes. Proc Natl Acad Sci USA. 2008; 105: 5022-5027.

17. Rassi A Jr, Rassi A, Marcondes de Rezende J. American trypanosomiasis (Chagas disease). Infect Dis Clin North Am. 2012; 26: 275-291.

18. Bern C. Chagas' Disease. N Engl J Med. 2015; 373: 456-466.

19. De la Cruz JJ, Villanueva-Lizama L, Dzul-Huchim V, Ramírez-Sierra M-J, Martinez-Vega $\mathrm{P}$, Rosado-Vallado $\mathrm{M}$, et al. Production of recombinan TSA-1 and evaluation of its potential for the immuno-therapeutic control of Trypanosoma cruzi infection in mice. Hum Vaccin Immunother. 2019; 15: 210-219.

20. Arce-Fonseca M, Carbajal-Hernández AC, Lozano-Camacho M, CarrilloSánchez SDC, Roldán F-J, Aranda-Fraustro A, et al. DNA vaccine treatment in dogs experimentally infected with Trypanosoma cruzi. J Immunol Res. 2020; 2020: 9794575

21. Dumonteil E, Herrera C, Tu W, Goff K, Fahlberg M, Haupt E, et al. Safety and immunogenicity of a recombinant vaccine against Trypanosoma cruzi in Rhesus macaques. Vaccine. 2020; 38: 4584-4591.

22. Humphreys G. Vaccination: rattling the supply chain. Bull World Health Organ. 2011; 89: 324-325

23. Levine MM. "IDEAL" vaccines for resource poor settings. Vaccine. 2011 29: D116-D125.

24. Rosales-Mendoza S, Angulo C, Meza B. Food-grade organisms as vaccine biofactories and oral delivery vehicles. Trends Biotechnol. 2016; 34: 124 136.

25. Maldonado E, Rojas DA, Morales S, Miralles V, Solari A. Dual and opposite roles of Reactive Oxygen Species (ROS) in Chagas disease: Beneficial on the pathogen and harmful on the host. Oxid Med Cell Longev. 2020; 2020: 8867701.

26. Rodrigues MM, Oliveira AC, Bellio M. The immune response to Trypanosoma cruzi: Role of Toll-like receptors and perspectives for vaccine development. J Parasitol Res. 2012; 2012: 507874

27. Tandon R, Chandra S, Baharia RK, Das S, Misra P, Kumar A, et al. Characterization of the proliferating cell nuclear antigen of Leishmania donovani clinical isolates and its association with antimony resistance. Antimicrob Agents Chemother. 2014; 58: 2997-3007.

28. Mazzeti AL, Capelari-Oliveira P, Bahia MT, Mosqueira VCF. Review on Experimental Treatment Strategies against Trypanosoma cruzi. J Exp Pharmacol. 2021; 13: 409-432.

29. Understanding Vaccine Trials.

30. Vaccine Development Table. The Children's Vaccine Initiative: Achieving the Vision. National Academies Press. 1993.

31. Teh-Poot C, Dumonteil E. Mining Trypanosoma cruzi Genome Sequences for Antigen Discovery and Vaccine Development. Methods Mol Biol. 2019; 1955: 23-34

32. Junqueira C, Caetano B, Bartholomeu DC, Melo MB, Ropert C, Rodrigues $\mathrm{MM}$, et al. The endless race betweenTrypanosoma cruziand host immunity: lessons for and beyond Chagas disease. Expert Rev Mol Med. 2010; 12.

33. Machado FS, Tyler KM, Brant F, Esper L, Teixeira MM, Tanowitz HB Pathogenesis of Chagas disease: time to move on. Front Biosci (Elite Ed). 2012; 4: 1743-1758.

34. Dumonteil E, Bottazzi ME, Zhan B, Heffernan MJ, Jones $K$, Valenzuela JG, et al. Accelerating the development of a therapeutic vaccine for human Chagas disease: rationale and prospects. Expert Rev Vaccines. 2012; 11: 1043-1055.

35. Vetter V, Denizer G, Friedland LR, Krishnan J, Shapiro M. Understanding modern-day vaccines: what you need to know. Ann Med. 2018; 50: 110-120.

36. Basombrío MA, Gómez L, Padilla AM, Ciaccio M, Nozaki T, Cross GA Targeted deletion of the gp72 gene decreases the infectivity of Trypanosoma cruzi for mice and insect vectors. J Parasitol. 2002; 88: 489-493.

37. Pérez Brandan C, Basombrío MÁ. Genetically attenuated Trypanosoma cruzi parasites as a potential vaccination tool. Bioengineered. 2012; 3: 242 246.

38. Rodríguez-Morales $\mathrm{O}$, Monteón-Padilla $\mathrm{V}$, Carrillo-Sánchez SC, et al. Experimental vaccines against Chagas disease: a journey through history. $J$ Immunol Res. 2015: 489758

39. Rodríguez-Morales O, Monteón-Padilla V, Carrillo-Sánchez SC, Rios-Castro M, Martínez-Cruz M, Carabarin-Lima A, et al. Experimental vaccines against Chagas disease: A journey through history. J Immunol Res. 2015; 2015 : 489758.

40. Bontempi I, Leal K, Prochetto E, Díaz G, Cabrera G, Bortolotti A, et al. Recombinant Mycobacterium bovis BCG is a promising platform to develop vaccines against Trypansoma cruzi infection. Clin Exp Immunol. 2020; 201 306-316.

41. Martinez-Campos V, Martinez-Vega $P$, Ramirez-Sierra MJ, Rosado-Vallado M, Seid CA, Hudspeth EM, et al. Expression, purification, immunogenicity, and protective efficacy of a recombinant Tc24 antigen as a vaccine against Trypanosoma cruzi infection in mice. Vaccine. 2015; 33: 4505-4012.

42. Matos MN, Sánchez Alberti A, Morales C, Cazorla SI, Malchiodi EL. A primeboost immunization with Tc52 N-terminal domain DNA and the recombinant protein expressed in Pichia pastoris protects against Trypanosoma cruzi infection. Vaccine. 2016; 34: 3243-3251.

43. Cerny N, Sánchez Alberti A, Bivona AE, De Marzi MC, Frank FM, Cazorla $\mathrm{SI}$, et al. Coadministration of cruzipain and GM-CSF DNAs, a new immunotherapeutic vaccine against Trypanosoma cruzi infection. Hum Vaccin Immunother. 2016; 12: 438-450.

44. Cazorla SI, Matos MN, Cerny N, Ramirez C, Alberti AS, Bivona AE, et al 
Oral multicomponent DNA vaccine delivered by attenuated Salmonella elicited immunoprotection against American trypanosomiasis. J Infect Dis. 2015; 211: 698-707

45. Aparicio-Burgos JE, Zepeda-Escobar JA, de Oca-Jimenez RM, EstradaFranco JG, Barbabosa-Pliego A, Ochoa-García L, et al. Immune protection against Trypanosoma cruzi induced by TcVac4 in a canine model. PLoS Negl Trop Dis. 2015; 9: e0003625.

46. Pereira IR, Vilar-Pereira G, Marques V, da Silva AA, Caetano B, Moreira $\mathrm{OC}$, et al. A human type 5 adenovirus-based Trypanosoma cruz therapeutic vaccine re-programs immune response and reverses chronic cardiomyopathy. PLoS Pathog. 2015; 11: e1004594.

47. Alberti AS, Bivona AE, Cerny N, Schulze K, Weißmann S, Ebensen T, et al Engineered trivalent immunogen adjuvanted with a STING agonist confers protection against Trypanosoma cruzi infection. NPJ Vaccines. 2017; 2

48. Padilla AM, Bustamante JM, Tarleton RL. CD8 ${ }^{+} \mathrm{T}$ cells in Trypanosoma cruzi infection. Curr Opin Immunol. 2009; 21: 385-390.

49. Limon-Flores AY, Cervera-Cetina R, Tzec-Arjona JL, Ek-Macias L, SánchezBurgos G, Ramirez-Sierra MJ. Effect of a combination DNA vaccine for the prevention and therapy of Trypanosoma cruzi infection in mice: role of CD4 and $\mathrm{CD}^{+}$T cells. Vaccine. 2010; 28: 7414-7419.

50. Tarleton RL. CD8 ${ }^{+} \mathrm{T}$ cells in Trypanosoma cruzi infection. Semin Immunopathol. 2015; 37: 233-238.

51. Malekian R, Sima S, Jahanian-Najafabadi A, Moazen F, Akbari V Improvement of soluble expression of GM-CSF in the cytoplasm of Escherichia coli using chemical and molecular chaperones. Protein Expr Purif. 2019; 160: 66-72.

52. Tripathi NK. Production and Purification of Recombinant Proteins from Escherichia coli. Chem Bio Eng Rev. 2016; 3: 116-133.

53. Park KY, Wi SJ. Potential of plants to produce recombinant protein products J Plant Biol. 2016; 59: 559-568

54. Gupta S, Salgado-Jimenez B, Lokugamage N, Vazquez-Chagoyan JC Garg, NJ. TcG2/TcG4 DNA Vaccine Induces Th1 Immu- nity Against Acute Trypanosoma cruzi Infection: Adjuvant and Antigenic Effects of Heterologous T. rangeli Booster Immunization. Front. Immunol. 2019; 10: 1456.

55. Aparicio-Burgos JE, Ochoa-García L, Zepeda-Escobar JA, Gupta S, Dhiman M, Martínez JS, et al . Testing the efficacy of a multi-component DNA-prime/ DNA-boost vaccine against Trypanosoma cruzi infection in dogs. PLoS Negl Trop Dis. 2011; 5: e1050.

56. Bhatia V, Garg NJ. Previously unrecognized vaccine candidates contro Trypanosoma cruzi infection and immunopathology in mice. Clin Vaccine Immunol. 2008; 15: 1158-1164.

57. Bode C, Zhao G, Steinhagen F, Kinjo T, Klinman DM. CpG DNA as a vaccine adjuvant. Expert Rev Vaccines. 2011; 10: 499-511.

58. Corral RS, Petray PB. CpG DNA as a Th1-promoting adjuvant in immunization against Trypanosoma cruzi. Vaccine. 2000; 19: 234-242.

59. Eickhoff CS, Giddings OK, Yoshida N, Hoft DF. Immune responses to gp82 provide protection against mucosal Trypanosoma cruzi infection. Mem Inst Oswaldo Cruz. 2010; 105: 687-691.

60. Mucci J, Carmona SJ, Volcovich R, Altcheh J, Bracamonte E, Marco JD, e al. Next-generation ELISA diagnostic assay for Chagas Disease based on the combination of short peptidic epitopes. PLoS Negl Trop Dis. 2017; 11: e0005972.

61. Bottino CG, Gomes LP, Pereira JB, Coura JR, Provance DW Jr, De-Simone SG. Chagas disease-specific antigens: characterization of epitopes in CRA FRA by synthetic peptide mapping and evaluation by ELISA-peptide assay. BMC Infect Dis. 2013; 13: 568

62. Elisei RMT, Matos CS, Carvalho AMRS, Chaves AT, Medeiros FAC, Barbosa $\mathrm{R}$, et al. Immunogenomic screening approach to identify new antigens for the serological diagnosis of chronic Chagas' disease. Appl Microbiol Biotechnol. 2018; 102: 6069-6080

63. El-Sayed NM, Myler PJ, Bartholomeu DC, Nilsson D, Aggarwal G, Tran
AN, et al. The genome sequence of Trypanosoma cruzi, etiologic agent of Chagas disease. Science. 2005; 309: 409-415.

64. De Pablos LM, Osuna A. Multigene families in Trypanosoma cruzi and their role in infectivity. Infection and immunity. 2012; 80: 2258-2564.

65. Serna C, Lara JA, Rodrigues SP, Marques AF, Almeida IC, Maldonado RA. A synthetic peptide from Trypanosoma cruzi mucin-like associated surface protein as candidate for a vaccine against Chagas disease. Vaccine. 2014 32: 3525-3532.

66. Heinson Al, Woelk CH, Newell M-L. The promise of reverse vaccinology. Int Health. 2015; 7: 85-89.

67. Villanueva-Lizama L, Dumonteil E. Harvesting the genome of Trypanosoma cruzi for the development of new treatments and vaccines. In: LópezCarramillo C, Marchat LA (eds) Comparative genomics in neglected human parasites. Nova Science Publishers, New York. 2013; 39-58.

68. Paba J, Santana JM, Teixeira ARL, Fontes W, Sousa MV, Ricart CAO. Proteomic analysis of the human pathogen Trypanosoma cruzi. Proteomics. 2004; 4: 1052-1059.

69. Michalik M, Djahanshiri B, Leo JC, Linke D. Reverse vaccinology: The pathway from genomes and Epitope predictions to tailored recombinant vaccines. Methods Mol Biol. 2016; 1403: 87-106.

70. Kazi A, Chuah C, Majeed ABA, Leow CH, Lim BH, Leow CY. Current progress of immunoinformatics approach harnessed for cellular- and antibody-dependent vaccine design. Pathog Glob Health. 2018; 112: 123131.

71. Enayatkhani M, Hasaniazad M, Faezi S, Gouklani H, Davoodian P, Ahmadi $\mathrm{N}$, et al. Reverse vaccinology approach to design a novel multi-epitope vaccine candidate against COVID-19: an in silico study. J Biomol Struct Dyn. 2021; 39: 2857-2872.

72. Flower DR, Macdonald IK, Ramakrishnan K, Davies MN, Doytchinova IA Computer aided selection of candidate vaccine antigens. Immunome Res. 2010; 6: S1.

73. Moise L, Cousens L, Fueyo J, De Groot AS. Harnessing the power of genomics and immunoinformatics to produce improved vaccines. Expert Opin Drug Discov. 2011; 6: 9-15.

74. Naz K, Naz A, Ashraf ST, Rizwan M, Ahmad J, Baumbach J, et al. PanRV Pangenome-reverse vaccinology approach for identifications of potential vaccine candidates in microbial pangenome. BMC Bioinformatics. 2019; 20 : 123.

75. Michel-Todó L, Reche PA, Bigey P, Pinazo M-J, Gascón J, Alonso-Padilla J. In silico design of an Epitope-based vaccine ensemble for Chagas disease. Front Immunol. 2019; 10: 2698.

76. Bruno L, Cortese M, Rappuoli R, Merola M. Lessons from Reverse Vaccinology for viral vaccine design. Curr Opin Virol. 2015; 11: 89-97.

77. Ferreira J, Porco A. Vacunas derivadas del análisis de los genomas: vacunología inversa. Interciencia. 2008; 33: 353-358.

78. Queiroz,AMV, Oliveira JWdF. Moreno CJ, Guérin, DMA, Silva MS. VLP Based Vaccines as a Suitable Technology to Target Trypanosomatid Diseases. Vaccines. 2021; 9: 220.

79. Chroboczek J, Szurgot I, Szolajska E. Virus-like particles as vaccine. Acta Biochim Pol. 2014; 61: 531-539.

80. Crisci E, Bárcena J, Montoya M. Virus-like particles: The new frontier of vaccines for animal viral infections. Veter Immunol. Immunopathol. 2012; 148: $211-225$

81. Gomes AC, Flace A, Saudan P, Zabel F, Cabral-Miranda G, El Turabi A et al. Adjusted Particle Size Eliminates the Need of Linkage of Antigen and Adjuvants for Appropriated T Cell Responses in Virus-Like Particle-Based Vaccines. Front. Immunol. 2017; 8: 226.

82. Grgacic EVL, Anderson DA. Virus-like particles: passport to immune recognition. Methods. 2006; 40: 60-65.

83. Zeltins A. Construction and characterization of virus-like particles: a review. 
Mol Biotechnol. 2013; 53: 92-107.

84. Pijlman GP. Enveloped virus-like particles as vaccines against pathogenic arboviruses. Biotechnol J. 2015; 10: 659-670.

85. Rosales-Mendoza S, Govea-Alonso DO, Monreal-Escalante E, Fragoso G, Sciutto E. Developing plant-based vaccines against neglected tropical diseases: where are we? Vaccine. 2012; 31: 40-48.

86. Ramos-Vega A, Monreal-Escalante E, Dumonteil E, Bañuelos-Hernández B, Angulo C. Plant-made vaccines against parasites: bioinspired perspectives to fight against Chagas disease. Expert Rev Vaccines. 2021: 1-16.

87. Callejas-Hernández F, Rastrojo A, Poveda C, Gironès N, Fresno M Genomic assemblies of newly sequenced Trypanosoma cruzi strains revea new genomic expansion and greater complexity. Sci Rep. 2018; 8: 14631.

88. Franzén O, Ochaya S, Sherwood E, Lewis MD, Llewellyn MS, Miles MA, et al. Shotgun sequencing analysis of Trypanosoma cruzi I Sylvio X10/1 and comparison with T. cruzi VI CL Brener. PLoS Negl Trop Dis. 2011; 5: e984.

89. Grisard EC, Teixeira SMR, de Almeida LGP, Stoco PH, Gerber AL, TalaveraLópez C, et al. Trypanosoma cruzi clone Dm28c draft genome sequence. Genome Announc. 2014; 2.

90. Berná L, Rodriguez M, Chiribao ML. Expanding an expanded genome: longread sequencing of Trypanosoma cruzi. Microb Genom. 2018; 4: e000177.

91. Zingales B, Andrade SG, Briones MRS, Campbell DA, Chiari E, Fernandes $\mathrm{O}$, et al. A new consensus for Trypanosoma cruzi intraspecific nomenclature: second revision meeting recommends Tcl to TcVI. Mem Inst Oswaldo Cruz. 2009; 104: 1051-1054

92. Lima L, Espinosa-Álvarez O, Ortiz PA, Trejo-Varón JA, Carranza JC, Pinto CM, et al. Genetic diversity of Trypanosoma cruzi in bats, and multilocus phylogenetic and phylogeographical analyses supporting Tcbat as an independent DTU (discrete typing unit). Acta Trop. 2015; 151: 166-177.

93. Zingales B. Trypanosoma cruzi genetic diversity: Something new for something known about Chagas disease manifestations, serodiagnosis and drug sensitivity. Acta Trop. 2018; 184: 38-52.

94. Messenger LA, Miles MA, Bern C. Between a bug and a hard place: Trypanosoma cruzi genetic diversity and the clinical outcomes of Chagas disease. Expert Rev Anti Infect Ther. 2015; 13: 995-1029.

95. Zingales B, Miles MA, Moraes CB, Luquetti A, Guhl F, Schijman AG, et al. Drug discovery for Chagas disease should consider Trypanosoma cruzi strain diversity. Mem Inst Oswaldo Cruz. 2014.

96. Vázquez-Chagoyán JC, Gupta S, Garg NJ. Vaccine development against Trypanosoma cruzi and Chagas disease. Adv Parasitol. 2011; 75: 121-146.

97. Sarkar B, Islam SS, Zohora US, Ullah AMA. Virus like particles- A recent advancement in vaccine development. The Microbiological Society of Korea 2019: 55: 327-343.

98. Alonso-Padilla J, Cortés-Serra N, Pinazo MJ, Bottazi ME, Abril M, Barreira $\mathrm{F}$. Strategies to enhance access to diagnosis and treatment for Chagas disease patients in Latin America Strategies to enhance access to diagnosis and treatment for Chagas disease patients in Latin America. Expert Rev Anti Infect Ther. 2019; 17: 145-157.

99. Bartsch SM, Bottazzi ME, Asti L, Strych U, Meymandi S, Falcón-Lezama JA et al. Economic value of a therapeutic Chagas vaccine for indeterminate and Chagasic cardiomyopathy patients. Vaccine. 2019; 37: 3704-3714.

100. Lee BY, Bacon KM, Wateska AR, Bottazzi ME, Dumonteil E, Hotez PJ. Modeling the economic value of a Chagas' disease therapeutic vaccine. Hum Vaccin Immunother. 2012; 8: 1293-1301

101. Vieira MC, Mendes FSNS, Mazzoli-Rocha F, Silva RS, Viana AMN, Frota $A X$, et al. Factors related to the discontinuation and mortality rates of a cardiac rehabilitation programme in patients with Chagas disease: a 6-year experience in a Brazilian tertiary centre. Trop Med Int Health. 2021; 26: 355365.

102.Lidani KCF, Sandri TL, Castillo-Neyra R, Andrade FA, Guimarães CM, Marques EN, et al. Clinical and epidemiological aspects of chronic Chagas disease from Southern Brazil. Rev Soc Bras Med Trop. 2020; 53: e20200225.

103. Gilbert NL, Gilmour H, Wilson SE, Cantin L. Determinants of non-vaccination and incomplete vaccination in Canadian toddlers. Hum Vaccin Immunother. 2017; 13: 1-7.

104. Guzman-Holst A, DeAntonio R, Prado-Cohrs D, Juliao P. Barriers to vaccination in Latin America: A systematic literature review. Vaccine. 2020; 38: $470-481$.

105. Jones K, Versteeg L, Damania A, Keegan B, Kendricks A, Pollet J, et al. Vaccine-linked chemotherapy improves benznidazole efficacy for acute Chagas disease. Infect Immun. 2018; 86.

106. Pan American Health Organization. Guidelines for the diagnosis and treatment of Chagas disease. Washington, D.C; PAHO. 2019.

107. Konduri V, Halpert MM, Liang D, Levitt JM, Cruz-Chan JV, Zhan B, et al Genetic adjuvantation of a cell-based therapeutic vaccine for amelioration of Chagasic cardiomyopathy. Infect Immun. 2017; 85.

108. Biter AB, Weltje S, Hudspeth EM, Seid CA, McAtee CP, Chen WH, et al. Characterization and stability of Trypanosoma cruzi 24-C4 (Tc24-C4), a candidate antigen for a therapeutic vaccine against Chagas disease. $J$ Pharm Sci. 2018; 107: 1468-1473.

109. DosReis GA. Evasion of immune responses by Trypanosoma cruzi, the etiological agent of Chagas disease. Braz J Med Biol Res. 2011; 44: 84-90.

110. Maleckar JR, Kierszenbaum F. Inhibition of mitogen-induced proliferation of mouse $\mathrm{T}$ and $\mathrm{B}$ lymphocytes by bloodstream forms of Trypanosoma cruzi. J Immunol. 1983; 130: 908-911.

111. Chaussabel D, Pajak B, Vercruysse V, Bisseye C, Garze V, Habib M, et al. Alteration of migration and maturation of dendritic cells and T-cell depletion in the course of experimental Trypanosoma cruzi infection. Lab Invest. 2003; 83: $1373-1382$.

112. Stempin C, Giordanengo L, Gea S, Cerban F. Alternative activation and increase of Trypanosoma cruzi survival in murine macrophages stimulated by cruzipain, a parasite antigen. J Leukoc Biol. 2002; 72: 727-734.

113. Ouaissi A, Ouaissi M, Tavares J, Cordeiro-Da-Silva A. Host cell phenotypic variability induced by trypanosomatid-para- site-released immunomodulatory factors: physiopathological implications. J Biomed Biotechnol. 2004; 2004: 167-174.

114. Garzon E, Borges MC, Cordeiro-Da-Silva A, Nacife V, Meirelles MN Guilvard E, et al. Trypanosoma cruzi carrying a targeted deletion of a Tc52 protein-encoding allele elicits attenuated Chagas' disease in mice. Immunol Lett. 2003; 89: 67-80.

115. Buscaglia CA, Campo VA, Frasch AC, Di Noia JM. Trypanosoma cruzi surface mucins: host-dependent coat diversity. Nat Rev Microbiol. 2006; 4 229-236.

116. Villanueva-Lizama LE, Cruz-Chan JV, Aguilar-Cetina ADC, HerreraSanchez LF, Rodriguez-Perez JM, Rosado-Vallado ME, et al. Trypanosoma cruzi vaccine candidate antigens Tc24 and TSA-1 recall memory immune response associated with HLA-A and -B supertypes in Chagasic chronic patients from Mexico. PLoS Negl Trop Dis. 2018; 12: e0006240.

117. Cruz-Chan JV, Villanueva-Lizama LE, Versteeg L, Damania A, Villar MJ, González-López C, et al. Vaccine-linked chemotherapy induces IL-17 production and reduces cardiac pathology during acute Trypanosoma cruzi infection. Sci Rep. 2021; 11: 3222.

118. Gupta S, Smith C, Auclair S, Delgadillo ADJ, Garg NJ. Therapeutic efficacy of a subunit vaccine in controlling chronic Trypanosoma cruzi infection and Chagas disease is enhanced by glutathione peroxidase over-expression. PLoS One. 2015; 10: e0130562.

119. H2020 project CRUZIVAX. Unl.pt.

120. Ubatec SA, Ponce M. UBATEC vacunas.

121. CRUZIVAX. Cruzivax.eu. 2020 